\title{
The Role of Digital Transformation in Development in Egypt
}

\author{
Sherif Kamel \\ The American University in Cairo, Cairo, Egypt \\ skamel@aucegypt.edu
}

Received date: 23 November 2020; Accepted date: 3 February 2021; Published date: 2 July 2021

Academic Editor: Fayez Ahmad Albadri

Copyright (C) 2021. Sherif Kamel. Distributed under Creative Commons Attribution 4.0 International CC-BY 4.0

\begin{abstract}
Innovation, creativity, and digital transformation have been gradually transforming societies for decades. They continue to have a significant role to play in business and socioeconomic development. Their impact on individuals and organizations has been remarkable in different industries and enterprises, especially in emerging markets, helping them become more agile and competitive while enabling a platform for growth and prosperity. This article demonstrates the role of digital transformation in development in Egypt, coupled with the associated opportunities and challenges given the repercussions of the Covid-19 pandemic that led to the acceleration of digital transformation across society. The article also highlights the importance and impact of supporting tech-based and tech-enabled startups, providing universal connectivity, investing in human capital, and availing a conducive environment to support entrepreneurship, creativity, innovation, and discovery.
\end{abstract}

Keywords: Innovation, Entrepreneurship, Acceleration, Digital Transformation, Shared Economy, Emerging Economies, Egypt.

\section{Introduction}

Through its ancient history that extends over 5000 years, Egypt witnessed massive information flows from the Rosetta stone and papyrus papers to the establishment of the Bibliotheca Alexandrina. During the Middle Ages, Arabic manuscripts became one of the most common means of information dissemination. In the early $19^{\text {th }}$ century, Egypt witnessed the first journal published, and established the first national archive system (Kamel, 1998a). However, until1985, Egypt was perceived as rich in scattered data but poor in analyzed information. Within the government as well as the private sector, computing was viewed as an end rather than a means. Also, accumulated bureaucracy through red tape was coupled with innovation islands in silos with no connecting bridges, restraining the production of information (Kamel, 1998b). All of that

Cite this Article as: Sherif Kamel (2021)," The Role of Digital Transformation in Development in Egypt ", Journal of Internet and e-Business Studies, Vol. 2021 (2021), Article ID 911090, DOI: 10.5171/2021.911090 
represented several windows of opportunities to address by taking the necessary actions and measures to realize the development that could transform the economy with its diversified nature, untapped potentials as well as business and socioeconomic opportunities.

Today, information and communication technologies (ICTs) are increasingly transforming societies worldwide into becoming more competitive, agile, dynamic, and able to adopt different models that allow them to compete locally and globally. Emerging ICTs have changed how people think, work, study, shop, communicate, get entertained, and in many ways, live. Consequently, these technologies offer an invaluable opportunity for business and socioeconomic development, and growth (Allan, 2020; Kamel and Rizk, 2019). As an emerging economy, Egypt has strived to achieve the potentials of ICTs since the 1960s. It has continuously invested in building and upgrading its infostructure and infrastructure to reposition itself as a strategic stakeholder in the continuously changing regional and global marketplaces (Petrazzini and Harindranath, 1996). Besides, with the growing and impactful influence of the digital natives and their tech-savvy, passionate, connected, and engaged generation, the prospects of digital transformation and accordingly the impact on the economy in specific and the society at large continue to represent an invaluable opportunity for Egypt to develop, grow and prosper (Rizk and Kamel, 2013).

In the early days of introducing computing to Egypt, the collective efforts of the government and the private sector supported by the civil society were focusing on technical issues and not on decision outcomes; the multi-sector coordination was poor, and the synergy among sectoral strategies was either weak or lacking. Given how important and useful ICTs have proven to be for socioeconomic development, especially for emerging markets, including Egypt, building the necessary national information infrastructure (infostructure) was a necessity. Besides, emerging innovative tools and applications presented a unique opportunity for inclusion and equality in addition to helping reduce the digital divide as well as improving the lives and livelihoods of the society (Kamel, 2020a).

\section{Building the ICT Infrastructure}

Since the early 1980s, Egypt has heavily invested in building and upgrading its technology infrastructure and national infostructure to become a platform and an enabler for its development and growth. An evolving process by design is iterative and regularly changing to keep pace with the continuous developments taking place in various technology applications and platforms, including the recent evolution of the fourth industrial revolution and the prospects enabled through the power and reach of artificial intelligence, the Internet of Things, data analytics, drones, blockchains, cloud computing, and robotics (Schwab, 2018; Faixó, 2018; Schwab, 2016).

Four decades ago, Egypt launched a national strategy to realize its socioeconomic developmental objectives and to address various challenges, including debt, illiteracy, inadequate infrastructure, and the need for structural reform. Over the years, the strategy was amended several times to accommodate the changes taking place locally and globally, with ICT continually perceived as a catalyst for the strategy design, development, and implementation (Rizk and Kamel, 2013). Consequently, in 1985, the government of Egypt established the Information and Decision Support Center (IDSC), a think-tank affiliated with the Cabinet of Egypt. The objective was to develop and implement, using a supply-push strategy, large nationwide informatics projects to support socioeconomic development (Azab et al., 2009).

The focus on the infostructure demonstrated the power of information in manipulating the discourse about socioeconomic reform (Stiglitz, 2002). It is important to note that before the 1980s, the government of Egypt dominated the supply of information. However, the number of entities generating information started to increase and their service quality was improving. Today, social media plays a significant role in that domain and is expected to play a key role, moving 
forward as part of the growing global trends, in the access to and democratization of knowledge (Von Hippel, 2005). During the period 1985-1995, a government-private sector partnership had a remarkable impact on Egypt's infostructure's build-up by establishing hundreds of informatics projects and centers in different public and private sector organizations across Egypt's 27 governorates and targeting socioeconomic development and growth. These projects were considered essential building blocks to develop a full-fledged infostructure capable of keeping pace with the global transformations in business and industry.

In 1999, ICT was identified as a priority at the highest policy level, and consequently, a new cabinet office was established; the Ministry of Communication and Information Technology (MCIT). During that time, the ICT sector was perceived as having transformed itself from an industry looking for support and subsidies into an industry contributing to the economy with a total of 5.2 billion US dollars received by the treasury in 2006 through the introduction of a portfolio of telecommunication services including expanding the universal internet access and mobile services as well as upgrading the fixed-line infrastructure of the fixed-line across the nation (Ismail et al., 2018).

These technologies offered the global community endless opportunities for job creation, economic development, growth, communication, and collaboration irrespective of time and distance barriers signaling, with the invention of the Internet and mobility, the early signs of acceleration of digital transformation (Allan, 2020; Friedman, 2016). These technologies have also been a source of regular disruption that prompted innovation, creativity, and discovery with massive implications on society (Kane et al., 2014). Accordingly, since the 1980s, disruption in the way societies operate has been taking place in different shapes and forms, but it was predominantly affected by the power and opportunities enabled by various emerging innovative technologies. However, it is important to note that during the past several decades, when people talked about disruption, they usually meant the impact that information and communication technologies had on individuals, organizations, and society (Kamel, 2020a).

\section{The Age of Disruption}

Since November 2019, the world has been hit by a disruptive pandemic that has affected developed and emerging economies with no discrimination. The disruption caused by Covid-19 was invisible and resembled a stealth attack. It started in Wuhan, China, and in no time, it spread all over the world. The pandemic has caused a global shock that has led to a slowdown in economies, affected financial markets, and disrupted supply and value chains, requiring immediate worldwide coordination and the development of collective measures to combat it. Meanwhile, the precautionary health and safety measures, including physical distancing and economic repercussions, have forced millions worldwide to work remotely or lose their jobs. The rapid change in how the society operates led people to observe the changes that the pandemic has caused in a few months compared to the collective efforts conducted by chief information and technology officers, experts, and professionals in the ICT industry for several decades.

It is worth noting that before the pandemic, the world was living in an age of pervasive and unprecedented uncertainty. However, it is nothing compared to what we have seen since the outbreak of the pandemic. The current disruption is impacting societies around the world politically, economically, and socially. It is still too early to tell, but the world will most probably witness a U-shaped recession with a potential recovery that will take around one and a half to two years awaiting the availability of a timely, tested, affordable, globally accessible, and distributed vaccine. That will hopefully be followed by an upswing in the global economy, which will vary from one country to another. In the meantime, countries are being hit by multiple rapid changes, including falling oil prices, disruptions to trade, volatile stock markets, and severe hits to businesses, which have forced governments to pass comprehensive and extraordinary policies aimed at stimulating their economies and preventing mass layoffs and business 
shutdowns, especially among small and medium-sized enterprises. Besides, the follow-up waves of the pandemic are adding to the challenges faced by different countries, each depending on the available resources and societal readiness.

\section{Is Egypt ready to be digitally transformed?}

There is nothing remotely good about societies being affected by a pandemic, the magnitude of which has rallied countries around the world to coordinate their efforts to work against a common enemy. However, many questions have arisen concerning the future: Can the coronavirus have some collateral positives? Are there opportunities that can be created through digital transformation? Is it an opportunity to autocorrect? How can an innovative and entrepreneurial tech-startup movement contribute to the development of the society of the future? What are the human capital requirements needed as an integral element in developing a nationwide entrepreneurial ecosystem that can transform the economy? How important investing in human and innovation capital is? What skill sets are required to be ready for a digital society driven by innovation and creativity? What is needed to be done and from where should it start so that whichever roadmap followed is effective and sustainable?

The above-mentioned questions have no answers addressing how the future will look like, especially with the acceleration of digital transformation over the last decade, which increased even more after the outbreak of Covid-19. One thing that became clear is that people do change. They are also ready to learn and deviate from legacies and lifelong habits if easy to use, accessible and affordable alternatives are made available. For starters, it became evident that the current crisis is already forcing people around the world to adapt and use different technology platforms much more than ever before, including the ones that they are not used to (Sharma, 2020; Faixó, 2018). Furthermore, the mergers of infotech and biotech prove that there are no boundaries to the prospects for what lies ahead. In addition, it will take a different leadership style across various economic sectors coupled with using innovative approaches to be able to navigate the emerging realities of the fourth industrial revolution, and become more resilient, agile, and competitive in a continuously changing global marketplace (Sharma, 2020; Kazim, 2019).

When it comes to Egypt, the recent developments since the pandemic outbreak have demonstrated the importance of assessing its ability to adopt digital transformation in government practices, business transactions, and across society to mitigate the impact of various disruptions (Wamda and Arabnet, 2020; Dcode, 2020). Consequently, developing and regularly enhancing the required infostructure and infrastructure to support and enable digital transformation in Egypt will be indispensable for individuals, organizations and societies, and more importantly, instrumental for the second tier of economic reforms following the ones that were successfully implemented during the period 2016-2019 (Kamel, 2020b).

The disruption caused by the pandemic should push Egypt collectively as a nation including the government as an enabler, the private sector as a driver, and the civil society as a supporter- to further coordinate their efforts and to think more creatively and ambitiously (Kamel, 2020a). This could include intensifying investments in key economic sectors, such as education, healthcare, and ICT, as well as upskilling and reskilling the capacities of one of the country's most precious assets, its human capital, to meet the requirements of digital transformation and the future of work. This would, in turn, help accelerate the development of several significant sectors such as agriculture, manufacturing, banking and finance, trade, retail, transportation, and logistics, all of which have enormous potentials to thrive and positively impact the economy (Kamel, 2020c). There is also an urgent need to support small and mediumsized enterprises and integrate the informal sector into the economy (Kamel and Abouseif, 2015). As the society moves forward while visualizing and projecting the new normal, the policies formulated and the decisions taken should be thoughtful and purposedriven to support a more robust and 
competitive private sector, help improve productivity, assist resilient businesses and industries, and enable a conducive environment for economic growth and a government that is digitally driven and focused on efficiency and the rationalization in the use of resources.

It is worth noting that before the pandemic, Egypt was on the right track, doing well from an economic perspective. The economic growth was at 5.6 percent during the fiscal year 2018/2019 and was projected to reach 6 percent in the fiscal year 2019/2020. The economy was among the best performing in emerging markets, and the macroeconomic indicators were all heading in a positive direction following a series of macroeconomic and structural reforms. Despite the pandemic's impact, Egypt is the only economy in the Middle East that showed positive growth during the fiscal year 2019/2020, reaching 3.6 percent. The government is determined to continue its progress and accelerate structural reforms. On that note, judging by the developments of the first quarter of 2020, digital transformation could play a significant role in the government's future reform plans as it navigates the current crisis and the follow-up waves of the pandemic while keeping an eye on launching another set of reforms that would not only build on the hard-won macroeconomic stability achieved over the past few years, but more importantly address the longstanding impediments to a competitive private sector-led economic transformation (Morgan, 2019).

Consequently, the next reforms should focus on reducing bureaucracy, red tape, and nontariff barriers; making finance more accessible; and facilitating private sector access to critical economic building blocks; all can benefit from a well-thought and wellintegrated digital transformation strategy and execution. Such access will allow the private sector to expand, given the diversified nature of Egypt's economy, leading to more job opportunities, inclusion, economic development, and growth that could help reduce poverty levels and boost development and growth (Kamel and Dutta, 2021).
It is worth noting that Egypt's population is growing at an annual rate of 1.9 percent, or over 2.4 million people. Technology access has been rapidly increasing across the country, with 59 percent and 99 percent internet and mobile penetration rates, respectively, and around 39.5 million people possessing smart phones. No less than 60 percent of the population is under the age of 30 , reflecting a young society in a nation that is home to more than 100 million citizens. These elements provide a unique opportunity for change and progress. With its energy, ambition, and passion, the intersection of youth, innovation, technology dissemination, utilization and adoption, coupled with a growing interest in self-employment and entrepreneurial activities could help create a platform for a tech-based and tech-enabled entrepreneurial ecosystem. Furthermore, the universal access to ICT across Egypt's 27 governorates could be an influential contributor and enabler for digital transformation by providing unlimited access to knowledge, development, and a vast array of opportunities (Kamel and Dutta, 2021).

\section{The Prospects of Digital transformation for Egypt}

Digital transformation offers ample opportunities for Egypt. However, innovation in general, and ICT in specific, cannot solve all the problems or meet all the economic and societal challenges that have developed over many decades (Al-Aees, 2019). While digital transformation represents an enabling environment that can make a difference, it should be supported by the required infrastructure, the skilled human capital, and the proper legal, regulatory, investment, governance, educational, security, and other support environments needed for an integrated ecosystem. The name of the game is to invest in creating a pool of tech-savvy entrepreneurs and scale-up the number of innovative tech-based and tech-enabled startups through the establishment of incubators across Egypt's private and public sector universities and higher education institutions. In these incubators, the role of youth, practitioners, academics, industry experts, policymakers, business leaders, mentors, investors, and innovators can never be discounted (Ismail et al., 2018). It is a 
collective effort in which everyone should be effectively engaged and empowered.

Digital transformation can help reshape economies and societies and improve their competitiveness by stimulating creativity and innovation, generating greater efficiencies, enhancing various services, and offering a platform for inclusive and sustainable development and growth (Berman and Marshall, 2014; Matt et al., 2015). Accordingly, Egypt has an opportunity to capitalize on digital transformation and realize the goals of its vision for the 2030 development strategy by (a) unleashing the potential of the private sector; (b) digitizing various government services, which can have the positive effects of facilitating access to services for citizens, improving efficiency, reducing bureaucracy, and assisting the government in combating corruption; and (c) leveraging human capital capacities, with a focus on emerging technologies and investing methodically in building Egypt's innovation capital (Kamel, 2020a). Besides, digitization can offer a seamless platform for customs and tax processes that can remove the impediments facing investors and businesses and help create a favourable environment that can attract more foreign direct investment; the latter has proven to be relatively difficult to achieve in recent years, especially when compared to pre-2011 levels. It is important to note that while digital transformation will result in many jobs being replaced by machines in the future, new technology-related jobs will be created (Matt et al., 2016). There will be a surge in the need for high-skilled labor. Therefore, policies must be in place to provide sufficient human capital development, healthcare, and social welfare to enable the labor force to embrace and adapt to the continuous changes taking place and have the capacities and skill sets to understand and make the most of the prospects enabled through emerging innovative technology platforms. In short, there will be a greater need for people who can better deal with machines that use advanced technologies (Schwab, 2018).

\section{Building a startup ecosystem}

The growing crowd of innovative and talented tech entrepreneurs in Egypt could be influential and actively participate in its digital transformation. The following is a sample of promising tech-based and techenabled startups that address critical issues of primary importance to society, such as transportation, financial technology (fintech), healthcare, logistics, and distribution.

In transportation, Swvl -established in 2017 and known as the Uber of buses- is a premium alternative to public transport in Egypt. Through a mobile app, customers can book fixed-rate and affordable bus rides on existing routes. This is an effective solution that is much needed, given the traffic and transportation challenges in Egypt's major cities. Swvl is now operating in Egypt, Kenya, Nigeria, Jordan and Pakistan.

In fintech, Paymob is an electronic payment enabler established in 2013 that offers integrated infrastructure solutions empowering the masses with instruments that increase financial inclusion, which can be a crucial pillar of economic growth. Fintech can help small and medium-sized enterprises -which make up around 80 percent of the country's firms- bridge financial inclusion gaps, move into the formal economy, and effectively improve their capacity to grow and compete. In Egypt, cash is king, and therefore represents one of the most attractive markets for fintech. The population's size -which includes a substantial unbanked segment, with no more than 15 percent of the adult population having a bank account, one of the world's lowest penetration ratesdemonstrates the growth potential. Fintech started growing in Egypt in 2008, providing solutions including electronic payments for peer-to-peer transfers and bills, payroll, pension, and social security payments; online purchases; and the proliferation of smart wallets (Abdel Meguid, 2020). Moreover, fintech can offer the unbanked segment valuable social services such as paying back their loans and transferring money through kiosks across the country. It is expected that Covid-19 will accelerate the move toward mobile services, which will have positive implications, including gradually integrating large segments of the informal economy.

In healthcare, Vezeeta, launched in 2012, is a digital booking and practice management 
platform for physicians, clinics, and hospitals in the Middle East and North Africa (MENA) region. In logistics, MaxAB, established in 2018 , is an e-commerce wholesale food and grocery marketplace using data-driven technologies and innovative supply chains to serve its customers. Finally, in distribution, Brimore, established in 2017, is a social commerce and parallel distribution platform that allows local suppliers to have nationwide coverage through a network of individual distributors, mainly housewives, selling products in their circles using omnichannel.

Egypt is a consumer of imported digital products and services, and an exporter of digital services, recording total exports of 3.67 billion US dollars in the fiscal year 2018/2019. However, post-pandemic, there will be a clear opportunity to reap the digital dividends, increase the contribution of the sector and expand its role with coordinated actions by different stakeholders, including the government, the private sector, and the civil society. Innovative technologies drive digital transformation and open a broad spectrum of inclusive development opportunities that narrow the division between the haves and the have nots (UN, 2020; Kamel, 2020a; Matt et al., 2016).

The biggest challenge for digital transformation in general and fintech in specific is culture. However, there are other challenges, including the unclear legal and regulatory environment, interoperability issues among different systems, and the minimal understanding, among many entrepreneurs, of the advantages of digital financial services (Abdel Meguid, 2020). Realizing the value of financial inclusion for socioeconomic development and growth, many governments and private sector institutions are taking steps to help the financial sector advance and overcome these challenges. There are many recently introduced initiatives and projects that support the digital transformation of financial services through increasing access to the required technological infrastructure, encouraging the development and use of innovative digital financial solutions, and increasing awareness of the benefits of fintech, among other digital platforms. Given the population's size, the prospects are great to transform Egypt's economy into a cashless one, transfer many of the informal sector transactions to the formal economy, reduce unemployment and poverty levels, and offer various financing options for micro, small and medium-sized enterprises (UN, 2020).

Furthermore, there is no doubt that people's habits, attitudes, and behaviors will change. There are already early signs of a general shift to digital platforms by both individuals and businesses. Since the outbreak of Covid-19, Egyptians have been using digital platforms to work, study, and shop like never before, and this trend is expected to gain momentum in the future. During the period April-August 2020, statistics from Egypt's National Telecommunications Regulatory Authority (NTRA) show a significant surge in internet usage, including 87 percent and 18 percent increases in home and mobile internet consumption, respectively. This is in addition to a 131 percent rise in web browsing and significant growth in the use of mobile applications, with a 376 percent increase in accessing educational portals and websites during the academic year 2019/2020. On this note, the government has already signaled that it will continue to invest heavily in ICT infrastructure to accommodate the proliferation in digital transformation and help stimulate the economy, including the volume of investments in internet speed -that is expected to increase to $40 \mathrm{Mbps}-$ which have reached 1.6 billion US dollars. Besides, the government targets increasing internet access, both mobile and fixed, to 75 percent of the population. It is worth noting that the ICT sector is a growing contributor to Egypt's economy, accounting for 4 percent of the GDP in the fiscal year 2018/2019, registering an increase of 14.3 percent from the previous fiscal year 2017/2018 (Kamel, 2020a; Dcode, 2020).

The impact of digital transformation is intended to go beyond connectivity to include economic empowerment, productivity enhancement and growth, while also increasing competitiveness (Berman and Marshall, 2014). This consists of the digital transformation of services through a state-ofthe-art infrastructure supported by a robust legislative framework that enables electronic commerce, proper governance, data security, 
as well as buyer and seller rights preservation. For example, some of the initial digitally transformed services nationwide will include notarizations, driving license renewals, and utility payments. These services will be available through various channels, including the government portal and a portfolio of mobile applications. Furthermore, Egypt Post can take advantage of the trust it has enjoyed among the society for more than 150 years, coupled with its proximity to citizens across the country through its 4,000 premises, to support micro, small and medium-sized enterprises by offering a variety of digital services. Other digital services in the line include (a) a comprehensive health insurance system; (b) a farmers' card to ensure the delivery of subsidies to their rightful beneficiaries, verify land acquisitions and cultivated areas to develop an integrated agricultural map, help measure the amount of water needed for agriculture, and clarify the gaps between production and consumption; and (c) a restructuring of the national tax system aiming to achieve justice and order.

\section{Conclusion}

Undoubtedly, the role of innovative technologies impacts individuals, organizations and the society at large, making it more accessible, knowledgeable, agile, resilient, and competitive. This article attempted to share Egypt's experience in building its infrastructure and infostructure including its precious human capital as the building blocks for digital transformation and transforming the country's socioeconomic prospects while benefiting from the opportunities offered through emerging and innovative technology platforms of the fourth industrial revolution. It emphasized the starting point and the most invaluable element in the equation, that is the importance of availing a well-established, innovationdriven, government-enabled, and private sector-led digital transformation strategy that will represent the launch pad in realizing inclusive economic development and sustainability.

\section{References}

- Abdel Meguid, M. (6 September 2020), Egypt launches TSFE sub-fund for financial services, digital transformation, [Online]. Daily News Egypt. [22 December 2020]. Available: https://dailynewsegypt.com/2020/09/ 06/egypt-launches-tsfe-sub-fund-forfinancial-services-digitaltransformation/

- Al-Aees, S (11 September 2019), Egypt eyes digitalization of industry but faces challenges. [Online]. Daily News Egypt, [25 December 2020]. Available: https://dailynewsegypt.com/2019/09/ 11/egypt-eyes-digitalisation-ofindustry-but-faces-challenges /

- $\quad$ Allan, K. (27 October 2020), How Egypt's digital transformation is creating business opportunities,[Online] CIO. [23 December 2020]. Available: https://www.cio.com/article/3587147.

- Azab, N., Kamel, S and Dafoulas, G. (2009), 'A suggested framework for assessing electronic government readiness in Egypt,' Electronic Journal of e-Government, 7 (1),11-28.

- Berman, Sand Marshall, A. (2014), 'The next digital transformation: from an individual-centered to an everyone-toeveryone economy,' Strategy \& Leadership, 42(5), 9-17.

- Dcode. (2020), 'Decoding the Economics of Covid-19,' a Dcode Economic and Financial Consulting published report.

- Faixó, F. H. (2018), 'Beyond digital transformation race,' Proceedings of the third Catalonian Economy and Business Congress, ISBN 978-84-09-04059-9, April 2018.

- Friedman, T. (2016), 'Thank you for being late,' New York: Farrar, Straus and Giroux.

- Ismail, A., Kamel, S and Wahba, K. (2018), 'The impact of technology-based incubators in creating a sustainable and scalable startup culture in emerging economies: a system thinking model,' Proceedings of the $32^{\text {nd }}$ International Business Information Management Association (IBIMA) Conference, ISBN 978-0-999-8551-1-9, 15-16 November 2018, Sevilla, Spain, 6375-6388. 
- Kamel, S. (2020a), 'Does digital transformation present an opportunity for Egypt to autocorrect?' policy paper, in rethinking Egypt's economy, Middle East Institute, Washington, DC, USA, October.

- Kamel, S. (2020b), 'Reform 2.0,' Viewpoint, Business Monthly, The Journal of the American Chamber of Commerce in Egypt, 37 (7), 10.

- Kamel, S. (2020c), 'FinTech: the NextGen platform for financial inclusion,' Viewpoint, Business Monthly, The Journal of the American Chamber of Commerce in Egypt, 37 (2), 14.

- Kamel, S. (1998a), 'Building the African information infrastructure,' Business Information Technology Management: Closing the International Divide, Parthasarathi Banerjee, Ray Hackney, Gurpreet Dhillon, and R. Jain (ed), New Delhi: Har-Anand Publications, 118-144.

- Kamel, S. (1998b), 'Building an information highway,' Proceedings of the $31^{\text {st }}$ Hawaii International Conference on System Sciences (HICSS), ISBN 0-76951874-5, 6-9 January, Hawaii, United States,31-41.

- Kamel S and Dutta, S. (2021), It is the strategy and societal readiness, not just technology adoption and acceleration, [Online] The NileView. [28 February 2021]. Available: https://sherifkamel.substack.com/p/the -nileview-0c0

- Kamel, S, and Abouseif, M. (2015), 'A study of the role and impact of cloud computing onsmall and medium-sized enterprises (SMEs) in Egypt,' a Microsoft Corporation research study, JanuaryAugust.

- $\quad$ Kamel, S, and Rizk, N. (2019), 'The role of innovative and digital technologies in transforming Egypt into a knowledgebased economy,' Handbook of Research on the Evolution of IT and the Rise of ESociety, Maki Habib (ed), Hershey: IGI Global, 86-400.

- Kane, G, C., Palmer, D., Phillips, A.N., Kiron, D and Buckley, N. (5 July 2014), Moving beyond marketing: generating social business value across the enterprise, [Online]. MIT Sloan Management Review and Deloitte University Press. [24 December
2020].Available:

https://www2.deloitte.com/cn/en/page

s/technology-media-and-

telecommunications/articles/strategy-

not-technology-drives-digital-

transformation.html.

- Kazim, FAB (2019), 'Digital transformation and leadership style: a multiple case study,'The ISM Journal of International Business, 3 (1), 24-33.

- Matt, C., Hess, T., and Benlian, A. (2015),'Digital transformation strategies,' Business \& Information Systems Engineering, 57 (5), 339-343.

- Matt, C., Hess, T., Benlian, A and Wiesbock, F. (2016) 'Options for formulating a digital transformation strategy,' MIS Quarterly Executive, 15 (2), 123-139.

- $\quad$ Morgan, B. (21 July 2019), 7 Examples of how digital transformation impacted business performance, [Online]. Forbes. [27 December 2020]. Available: https://www.forbes.com/sites/blakemo rgan/2019/07/21/7-examples-of-howdigital-transformation-impactedbusinessperformance/?sh=76f1918651bb

- Petrazzini, B and Harindranath, G. (1996), 'Information infrastructure initiatives in emerging economies: the case of India,' The National Information Infrastructure Initiatives, Brian Kahin and Ernest Wilson (ed), Cambridge: Massachusetts Institute of Technology Press, 217-260.

- Rizk, N and Kamel, S. (2013), 'ICT and building a knowledge society in Egypt,' International Journal of Knowledge Management, 9 (1), 1-20.

- Sharma, K. (2020), 'Digital transformation,' International Journal of Innovative Research in Technology, 6 (9),119-122.

- Schwab, K. (2018), 'Shaping the future of the fourth industrial revolution,' London: Penguin Random House.

- Schwab, K. (2016), 'The fourth industrial revolution,' London: Penguin Random House.

- Stiglitz, J. (2002), 'Transparency in government, the right to tell: the role of mass media in economic development,' 
Washington DC: World Bank Publications, 27-44.

- United Nations. (2020), 'The Impact of COVID-19 on the Arab Region, An Opportunity to Build Back Better,' a United Nations published policy brief.
- Von Hippel, E. (2005), 'Democratizing innovation,' Cambridge, MA: MIT Press.

- Wamda and Arabnet. (2020), 'The impact of the Covid-19 outbreak on the entrepreneurship ecosystem,' a Wamda and Arabnet published report. 